\title{
FE-MODELLING OF A CONTACT LAYER BETWEEN ELEMENTS JOINED IN PRELOADED BOLTED CONNECTIONS FOR THE OPERATIONAL CONDITION
}

\author{
Rafał Grzejda ${ }^{1}$ \\ 1 Faculty of Mechanical Engineering and Mechatronics, West Pomeranian University of Technology, Szczecin, \\ 19 Piastów Ave., 70-310 Szczecin, Poland, e-mail: rafal.grzejda@zut.edu.pl
}

Received: 2014.09 .25

Accepted: 2014.10.25

Published: 2014.12.01

\begin{abstract}
Modelling and calculations of a contact layer between elements joined in a preloaded bolted connection for the operational condition are presented. The physical model of the bolted connection is based on a flexible flange element that is joined with a rigid support by means of the no-bolt model (at the assembly stage) or the rigid body bolt model (at the operational stage). The contact layer between joined elements is described as the nonlinear Winkler model. The contact joint model considering an experimental normal elastic characteristic is presented. Examples of normal contact pressure and normal contact deformations distributions are contained.
\end{abstract}

Keywords: bolted connection, contact layer, assembly condition, operational condition.

\section{INTRODUCTION}

Preloaded bolted connections are an excellent alternative to other structural joints used in mechanical engineering. By the suitably carried out pretensioning process it is possible to prevent both the phenomenon of loosening the connection [1] or its leakage phenomenon [2]. Therefore, works on modelling of the contact layer between elements joined in such connections are very important.

Currently, in modelling of the contact joint in bolted connections the finite element systems are often used [3-5]. However, using standard contact elements available in these systems, only constant stiffness coefficients for each contact element at the contact surface can be taken into account. Meanwhile, in the analysis of the contact of elements joined in the bolted connection with an experimentally defined characteristic [6], it is necessary to take into consideration variations of stiffness coefficients for each element of the contact layer. Then creation of specific calculation procedures and using them in conjunction with calculations carried out in the finite element computer system is required.
In the present paper the method for individual modelling of elastic properties of the contact layer's elements is proposed. The study is conducted on the example of the contact joint of elements in the preloaded bolted connection loaded externally by a normal force.

\section{PHYSICAL MODEL OF THE BOLTED CONNECTION}

A general structure of the bolted connection model is illustrated in Figure 1. The model is based on a fragment of a flexible flange element that is fastened to a rigid support by means of a bolt. Calculations are carried out in two stages. During tightening the connection, the bolt is modeled only as an input force (Figure 1b). However, in the operational condition, the bolt is treated as the rigid body bolt model [7] (Figure 1c).

A nonlinear contact layer between the flange element and the support is modeled as the Winkler model, which is defined by means of a set of $j(j=1,2, \ldots, l)$ one-sided spring elements, described by the following relationship:

$$
R_{j}=A_{j} \cdot p_{n j}=A_{j} \cdot f\left(u_{n j}\right)
$$


a)

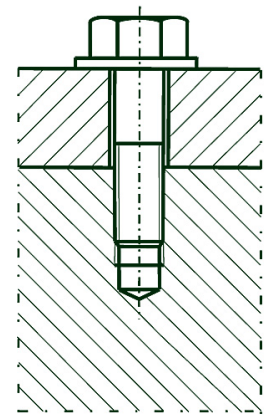

b)

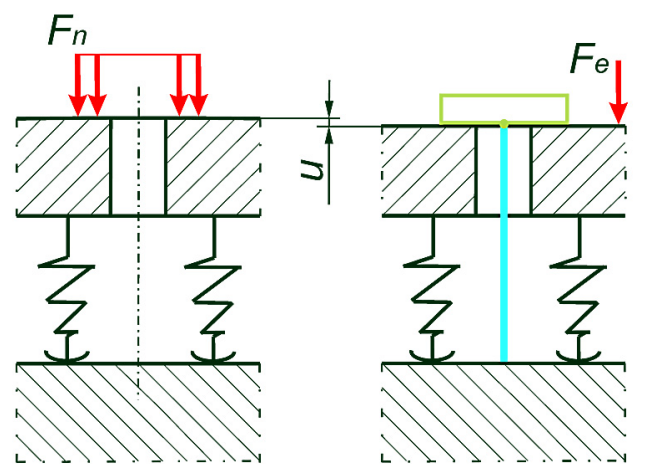

Fig. 1. Fragment of a bolted flange connection: a) diagram, b) physical model for the assembly condition, c) physical model for the operational condition $\left(F_{n}-\right.$ preload, $F_{e}$ - external normal load, $u$ - initial deformation of the bolted connection)

where: $R_{j}$ - the force in the centre of the $\mathrm{j}$-th elementary contact area,

$p_{n j}-$ normal contact pressure at the $\mathrm{j}$-th elementary contact area,

$u_{n j}$ - normal deformation of the $\mathrm{j}$-th nonlinear spring element,

$A_{j}$ - the j-th elementary contact area.

Structuring the contact layer model is run in the following steps:

- division of the contact surface between the flange and the support (Figure 2a) into elementary contact areas (Figure $2 \mathrm{~b}$ ),

- assignation mesh nodes in the centers of gravity of elementary contact areas (Figure 2b),

- insertion of nonlinear springs at the nodes identified in the previous step,

- creation of the 2D finite element mesh on the contact surface (Figure 2c).

Based on the 2D finite element mesh on the contact surface between the flange and the support, a uniform 3D finite element mesh for all the volume of the flange is generated.
The equation of system equilibrium (Figure 1) can be written in the form:

$$
\boldsymbol{K} \cdot \boldsymbol{q}=\boldsymbol{p}
$$

where: $\boldsymbol{K}$ - the stiffness matrix,

$q$ - the displacements vector,

$\boldsymbol{p}$ - the loads vector.

Assuming the division of the model into three subsystems ( $\boldsymbol{B}$ - the bolt, $\boldsymbol{F}$ - the flange element, $\boldsymbol{C}$ - the contact layer), the equation (2) can be rewritten as follows:

$$
\left[\begin{array}{ccc}
\boldsymbol{K}_{B B} & \boldsymbol{K}_{B F} & \mathbf{0} \\
\boldsymbol{K}_{F B} & \boldsymbol{K}_{F F} & \boldsymbol{K}_{F C} \\
\mathbf{0} & \boldsymbol{K}_{C F} & \boldsymbol{K}_{C C}
\end{array}\right] \cdot\left[\begin{array}{l}
\boldsymbol{q}_{B} \\
\boldsymbol{q}_{F} \\
\boldsymbol{q}_{C}
\end{array}\right]=\boldsymbol{p}
$$

where: $\boldsymbol{K}_{B B}, \boldsymbol{K}_{F F}, \boldsymbol{K}_{C C}-$ the stiffness matrices of subsystems $\boldsymbol{B}, \boldsymbol{F}$ and $\boldsymbol{C}$,

$\boldsymbol{K}_{B F}, \boldsymbol{K}_{F B}, \boldsymbol{K}_{F C}, \boldsymbol{K}_{C F}$ - the matrices of elastic couplings among subsystems $\boldsymbol{B}, \boldsymbol{F}$ and $\boldsymbol{C}$, $\boldsymbol{q}_{B}, \boldsymbol{q}_{F}, \boldsymbol{q}_{C}-$ the displacements vectors of subsystems $\boldsymbol{B}, \boldsymbol{F}$ and $\boldsymbol{C}$. a)

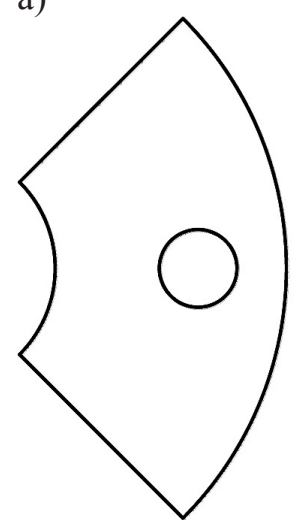

b)

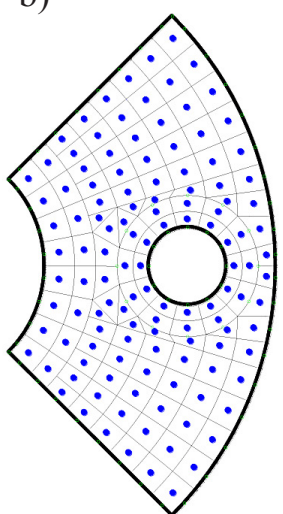

c)

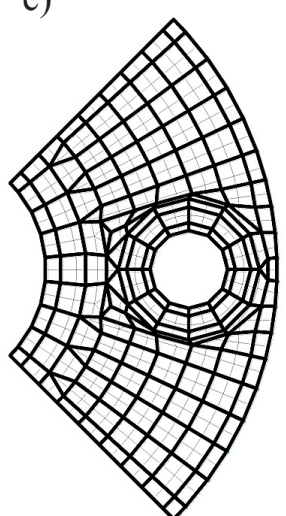

Fig. 2. Creating of the finite element mesh at the contact surface: a) real contact area, b) elementary contact areas, c) scheme of the mesh 
At the assembly stage, the system is composed of only two subsystems ( $\boldsymbol{F}$ and $\boldsymbol{C}$ ), preloaded by the force $F_{n}$ (Figure 1b). Then the equation (3) is reduced to the form:

$$
\left[\begin{array}{ll}
\boldsymbol{K}_{\mathrm{FF}} & \boldsymbol{K}_{\mathrm{FC}} \\
\boldsymbol{K}_{\mathrm{CF}} & \boldsymbol{K}_{\mathrm{CC}}
\end{array}\right] \cdot\left[\begin{array}{l}
\boldsymbol{q}_{\mathrm{F}} \\
\boldsymbol{q}_{\mathrm{C}}
\end{array}\right]=\left[\begin{array}{c}
\boldsymbol{F}_{n} \\
\mathbf{0}
\end{array}\right]
$$

At the operational stage, the preloaded system is loaded by a normal external force $F_{e}$. Then the loads vector $\boldsymbol{p}$ can be written as:

$$
\boldsymbol{p}=\left[\begin{array}{c}
\mathbf{0} \\
\boldsymbol{F}_{e} \\
\mathbf{0}
\end{array}\right]
$$

Thus, the equation (3) can be converted to the formula:

$$
\left[\begin{array}{ccc}
\boldsymbol{K}_{B B} & \boldsymbol{K}_{B F} & \mathbf{0} \\
\boldsymbol{K}_{F B} & \boldsymbol{K}_{F F} & \boldsymbol{K}_{F C} \\
\mathbf{0} & \boldsymbol{K}_{C F} & \boldsymbol{K}_{C C}
\end{array}\right] \cdot\left[\begin{array}{c}
\boldsymbol{q}_{B} \\
\boldsymbol{q}_{F} \\
\boldsymbol{q}_{C}
\end{array}\right]=\left[\begin{array}{c}
\mathbf{0} \\
\boldsymbol{F}_{\boldsymbol{e}} \\
\mathbf{0}
\end{array}\right]
$$

Both in the assembly and the operational condition, by solving the system of equations one obtains the displacements vector $\boldsymbol{q}_{C}$ :

$$
\boldsymbol{q}_{C}=\operatorname{col}\left(u_{n 1}, u_{n 2}, \ldots, u_{n j}, \ldots, u_{n l}\right)
$$

In the next step, reactions $R_{j}$ can be computed based on the relationship (1).

Solution of equations (4) and (6) is conducted in an iterative process using the secant method. In the case of the bolt tightening, the linearization runs according to the way shown in Figure 3a, starting from the origin of the coordinate system. And in the case of the operational stage, it starts with the working points $W P_{j}$ corresponding to the preload of the $j$-th nonlinear spring element.
The linearization process is kept running until the following condition has been met:

$$
\left|\frac{R_{\alpha}^{\prime}-R_{\alpha}}{R_{\alpha}}\right| \leq \varepsilon
$$

where: $R_{\alpha}^{\prime}$ - the reaction in the $\mathrm{j}$-th nonlinear spring obtained from the linearization, $\alpha$ - the index dependent on the case of the calculation process $(\alpha \in\{j, m j\})$, $\varepsilon$ - the admissible error of the linearization.

The diagram of iterative calculations of the bolted connection is shown in Figure 4.

\section{EXAMPLE CALCULATIONS}

According to the presented method, computations of a bolted connection of a flange shown in Figure 5 with a rigid support were realized. The subject of the research is a connection of a quarter of the flange EN 1092-1/01/DN25/PN6/ S235JR [8] with the rigid support performed by means of the bolt M10 of mechanical property class 5.6. The preload of the bolt $F_{n}$ is equal to $14,9 \mathrm{kN}$ and it is set down on the base of Polish Standard [8]. The surface area of preload influence $A_{n}$ is equal to $69,75 \pi \mathrm{mm}^{2}$ and it is set down on the base of Polish Standard [9]. After the preloading process, the connection is loaded by a normal force $F_{e}$ equal to $10 \mathrm{kN}$ as shown in Figure 5.

Calculations were carried out by means of the Midas NFX 2014 finite element program. The bolt is modeled with two types of elements: a)

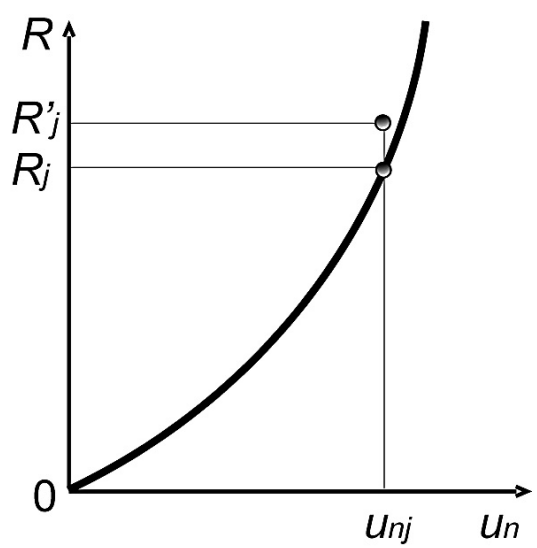

b)

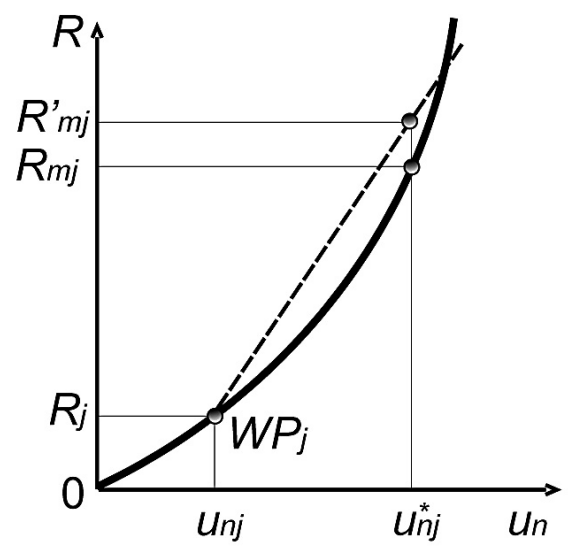

Fig. 3. Linearization of a curve by the secant method: a) in the case of the assembly condition, b) in the case of the operational condition 


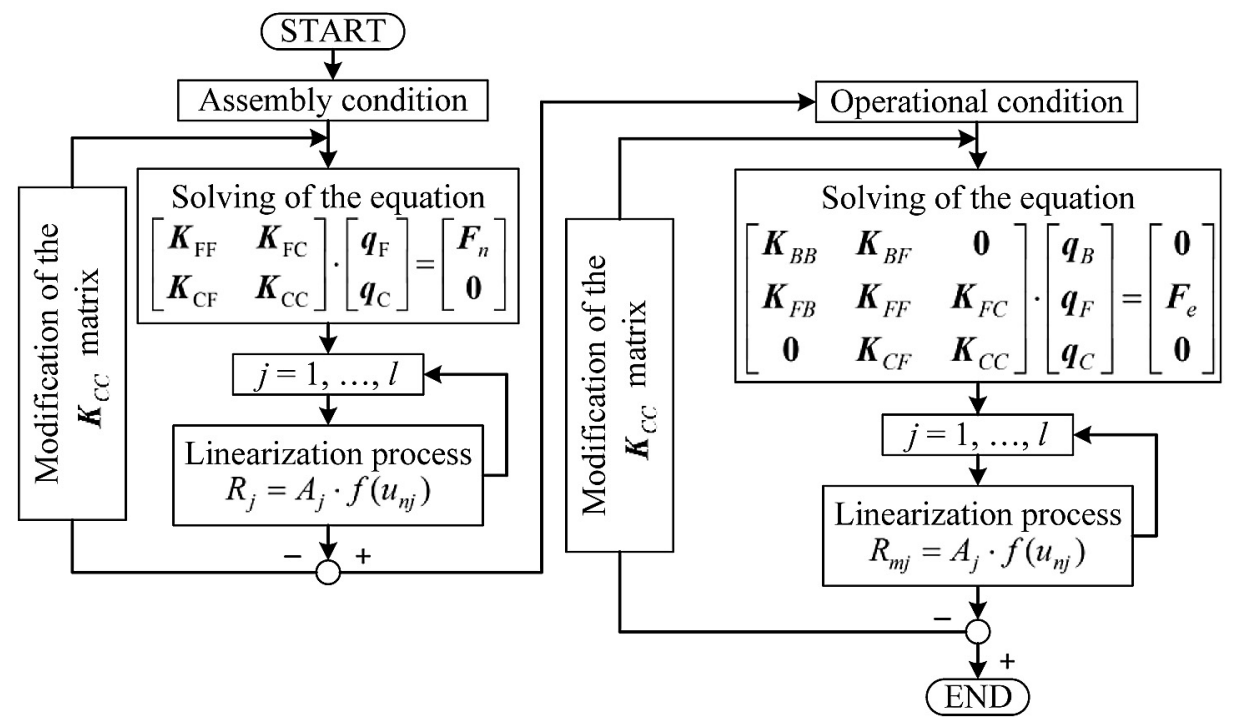

Fig. 4. Block diagram of the calculation process

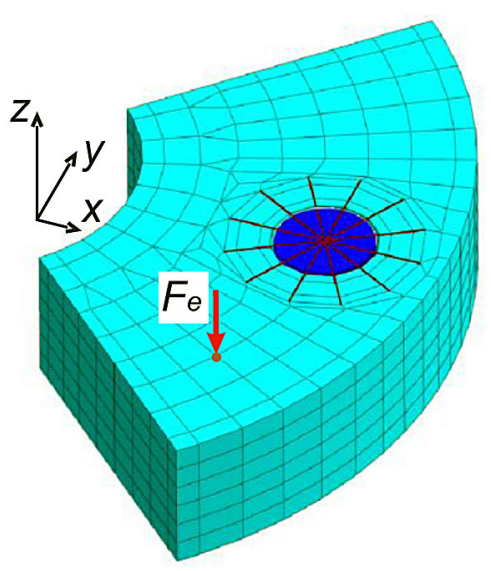

Fig. 5. FE-model of the tested bolted connection
- the plain part of the bolt is treated as a bar element,

- the bolt head is treated as a rigid element.

Elastic properties of the nonlinear contact layer are described as the following power function (obtained for a sample contact of elements joined in a multi-bolted connection [6]):

$$
R_{j}=A_{j} \cdot\left(3,428 \cdot u_{n j}^{1,657}\right)
$$

As results of calculations, normal contact pressure and normal contact deformations distributions for two tested conditions were received. The graphs were presented in Table 1.

Table 1. Results of calculations

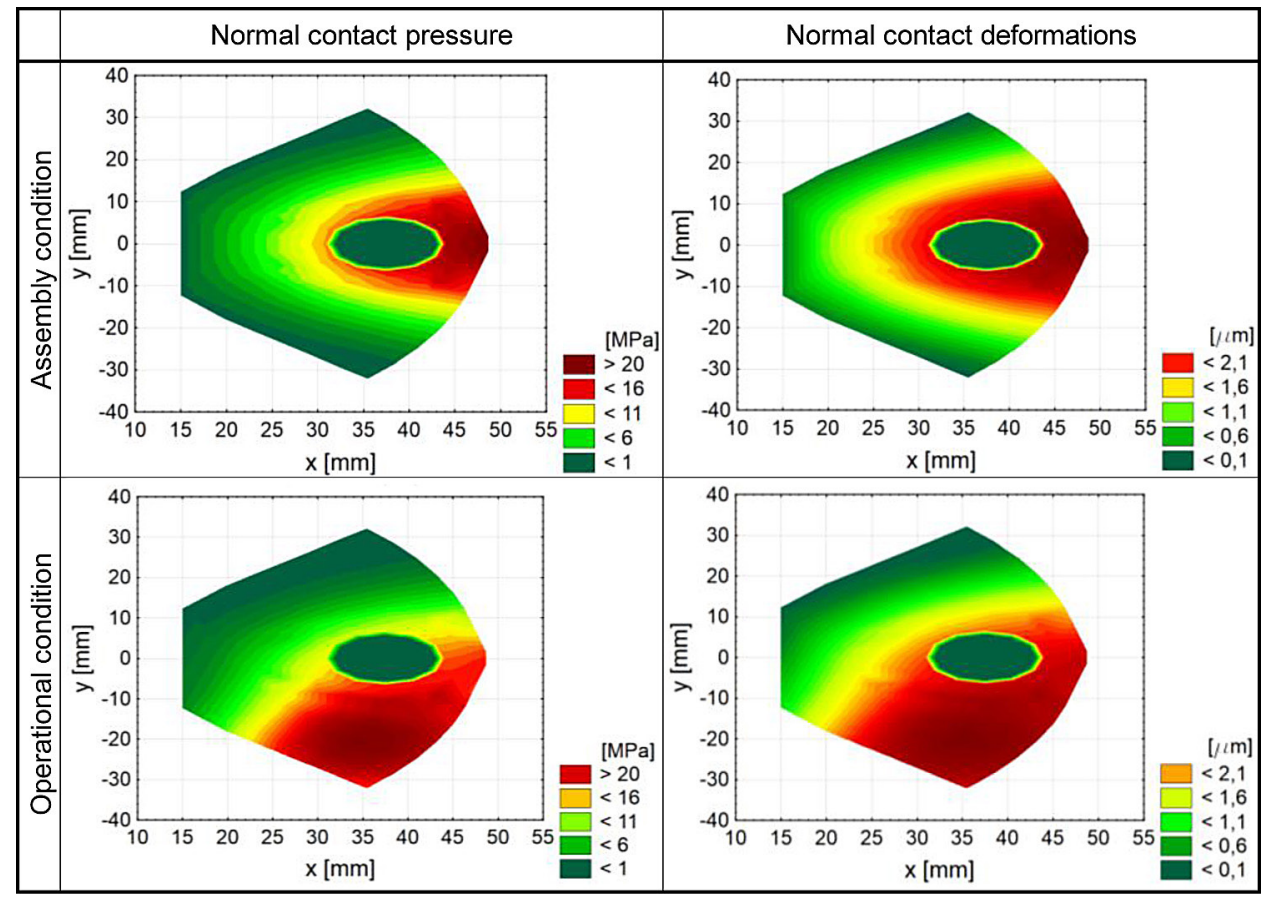




\section{CONCLUSIONS}

In the paper a procedure of computations of a contact joint between elements in a bolted connection with the use of its experimental normal characteristic is presented. Calculations were related to the assembly stage and the operational stage of the connection. In the model only contact stiffness in a direction normal to the contact surface were taken into account.

However, it is also possible to accommodate tangential contact stiffness and friction into the model. Results of works on development of the model will be published in future articles.

\section{REFERENCES}

1. Gardyński L., Nieoczym A.: Workplace research on the quality of screwing-in head (in Polish). Postępy Nauki i Techniki, 7, 2011, 120-126.

2. Izvolenskii E.V., Petrov R.A.: Determination of tightening parameters of threaded leak-tight joints. Chemical and Petroleum Engineering, 41 (1-2), 2005, 85-86.
3. Caliskan M.: Evaluation of bonded and bolted repair techniques with finite element method. Materials \& Design, 27 (10), 2006, 811-820.

4. Chakherlou T.N., Razavi M.J., Aghdam A.B.: On the variation of clamping force in bolted double lap joints subjected to longitudinal loading: A numerical and experimental investigation. Strain, 48 (1), 2012, 21-29.

5. Shi G., Shi Y., Wang Y., Bradford M.A.: Numerical simulation of steel pretensioned bolted end-plate connections of different types and details. Engineering Structures, 30 (10), 2008, 2677-2686.

6. Grzejda R., Cieloszyk J.: Determination of normal flexibility characteristics of surfaces ' contact with the specified surface texture (in Polish). Bulletin of the Military University of Technology, 63 (3), 2014, 175-187.

7. Grzejda R.: FE-modelling of bolts in bolted joints for the assembly condition (in Polish). Mechanik, 87 (8-9), 2014, 672-675.

8. PN-EN-1092-1:2010: Flanges and their joints Circular flanges for pipes, valves, fittings and accessories, PN designated - Part 1: Steel flanges.

9. PN-EN ISO 7091:2003: Plain washers - Normal series - Product grade C. 